\title{
Non-CPAP, non surgical therapies in obstructive sleep apnoea
}

\author{
Chandimani Undugodage $^{1}$ \\ Journal of the Ceylon College of Physicians, 2012, 43, 41-43
}

\section{Introduction}

Obstructive sleep apnoea (OSA) is a common condition that affects about $5 \%$ of the population world wide $^{1}$. In Sri Lanka the awareness for OSA is increasing with a significant number of patients with OSA being identified. In OSA the already narrow pharynx closes during sleep leading to apnoea. This is usually associated with reduction in oxygen saturation. These repeated anoxic and re-oxygenation events lead to neuro-hormonal changes with increased secretion of cortisol and epinephrins. This would lead to metabolic and cardiovascular events associated with OSA. The consequences are poor sleep, daytime somnolence and reduced productivity. These patients also have a high risk of developing ischemic heart disease, stroke, refractory hypertension, poor glycemic control, impotence etc. Recognition and treatment of OSA is vital in the overall management of patients.

The cardinal features of OSA are Snoring, Somnolence (daytime) and Sleep apneas(3 S's). OSA can be diagnosed by an overnight polysomnography by looking at the number of apneas and hypopnoeas. Apnea in adults is scored when there is a drop in the peak signal excursion by $\geq 90 \%$ of pre-event baseline using an oronasal thermal sensor or an alternative apnea sensor, for $\geq 10$ seconds. Hypopnea is scored when the peak signal excursions drop by $\geq 30 \%$ of pre-event baseline measuring nasal pressure or an alternative sensor, for $\geq 10$ seconds in association with either $\geq 3 \%$ arterial oxygen desaturation or an arousal.

The Apnoea Hypopnoea Index (AHI), which is the numberofapnoeas/hypopnoeas per hour is used to categorize OSA as mild ( $\mathrm{AHI} 5-15)$, moderate (AHI 15-30), and severe $\mathrm{AHI}(>30)$

The gold standard of therapy is CPAP ${ }^{2}$. (Continuous Positive Air way Pressure). CPAP is administered via a machine while the patient is asleep; the continuous jet of air keeps the pharynx open thereby alleviating apnoeas. However only $50 \%$ of patients take up CPAP therapy. Most find it cumbersome. In the local setting one of the biggest constraints to the use of CPAP is the cost of a machine. When functioning in a resource limited setting we have to look at other

\footnotetext{
${ }^{1}$ Senior Registrar, Respiratory Medicine, Central Chest Clinic, Colombo.
}

viable options to manage these patients. Surgery is an alternative for treatment of OSA. However some patients are reluctant undergo surgery. There are nonsurgical options such as weight reduction, positional therapies, mandibular advancement devices, tongue retaining devices, pharyngeal muscle strengthening, pharmacotherapy and nasal dilators for treatment of OSA. This article aims to look at these alternative methods of treatment based on "ERS task force report".

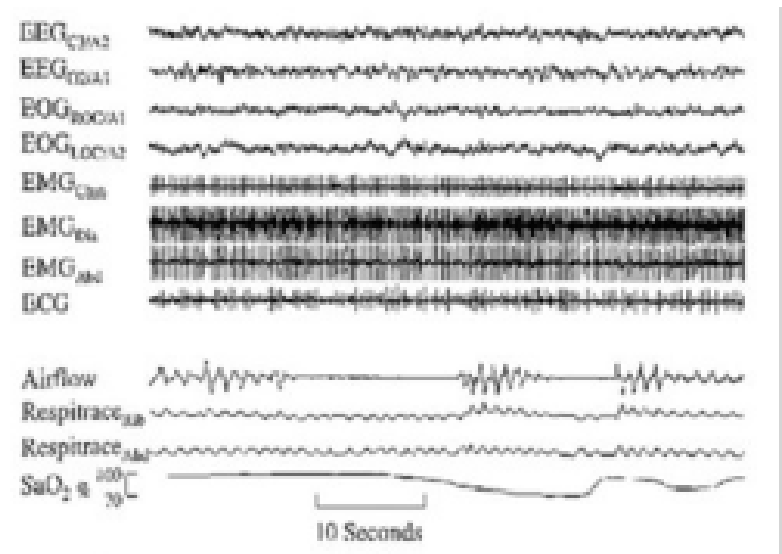

Figure 1. An example of an apnoea. Note the total cessation of airflow lasting for more than 10 seconds with preserved chest and abdominal movements.

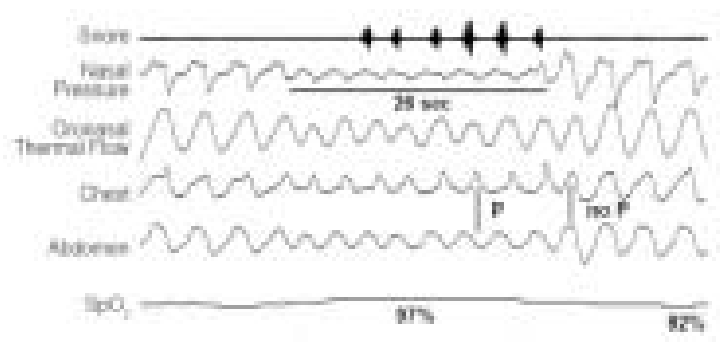

Figure 2. An example of a hypopnea. There is a 26 second long reduction in airflow with $5 \%$ desaturation associated with snoring.

\section{Weight reduction}

In OSA there is narrowing and closure of the pharynx. The deposition of fat in the pharynx as a consequence of obesity, decrease the pharyngeal patency, thereby facilitating pharyngeal obstruction. 
Weight reduction will decrease the critical closing pressure (Pcrit) and reduce the severity of OSA ${ }^{5}$. In diet intervention studies a mean BMI reduction of $4.7 \pm 2.5$ was accompanied by a decrease of AHI by $21 \pm 13$

Surgical intervention studies show a much higher reduction in $\mathrm{BMI}$ and the $\mathrm{AHI}$. In pharmaceutical intervention studies change in BMI was between 1.8 - 2.6, accompanied by a decrease in $\mathrm{AHI}$ between $2.8-16.3^{3}$. In OSA weight reduction is recommended as it is an important risk factor for other conditions.

\section{Positional therapy}

The number and duration of respiratory disturbances depend on body position and sleep stage. Ventilatory drive is also dependent on body position. There is a positive effect of a lateral position during sleep. Positional OSA (Defined as supine AHI at least twice as that of lateral position) has a prevalence of about $50 \%{ }^{6}$. These patients tend to have a lower $\mathrm{AHI}$, are younger and less obese ${ }^{7}$. The treatment is to avoid the supine position during sleep. Different devices such as tennis balls on the back, vests, positional alarms and pillows are used to avoid supine position.

However studies have shown that effectiveness is limited. Two uncontrolled studies suggested some improvement of sleep stages or daytime symptoms with positional therapy ${ }^{8,9}$.

\section{Mandibular advancement devices (MAD)}

This is a device that is fitted into the mouth at night so that the patient has it on while asleep. This pushes the jaw forward therefore the oropharynx is prevented from closing. The aim is to widen the upper airways to maintain airway patency thereby alleviating apneas. This will also reduce snoring. There are promising results with MAD with regard to reduction in apneas, daytime somnolence and snoring ${ }^{10-14}$.

MAD treatment reduced sleep apneas compared with placebo in all the studies. In all the studies the number of patients whose $\mathrm{AHI}$ reduced to $<5$ ranged from $19-75 \%$ and $\mathrm{AHI}$ was $<10$ in $30-94 \%$ of patients. Subjective daytime somnolence decreased with the use of MAD. Interestingly the effect on sleepiness with MAD was comparable with that of CPAP ${ }^{14-19}$. Snoring was better controlled with CPAP than MADs but MADs were better than placebo ${ }^{11,12}$. The studies have shown promising results on the effects of blood pressure, cardiac function, endothelial function and markers of oxidative stress with the use of MADs.
There are side effects to these devices such as jaw discomfort, tooth tenderness, increased salivation and temporary occlusal changes. As for compliance $76 \%$ continued treatment after 1 year $^{21}$ and $65 \%$ were using the device after 4 years ${ }^{20}$. The compliance with MADs is higher than that of CPAP ${ }^{14,19}$.

MADs are recommended for the treatment in those with mild to moderate OSA. The device should be custom made and should advance the mandible by at least $50 \%$ of the maximum protrusion. Reassessment with a repeat sleep study is necessary after starting on this treatment, as success should be measured objectively without going by symptoms alone. This is especially important in those with severe disease.

\section{Tongue retaining devices (TRD)}

TRD is an oral appliance that keeps the tongue anteriorly in mouth thereby widening the upper airway during sleep. There are only a few studies done in this area. One RCT showed a similar reduction of apneas when comparing MDAs with TRDs ${ }^{22}$. However patients preferred MDAs. TRDs are not routinely recommended in OSA. But they can be used in selected patients with mild to moderate OSA when other treatments have failed or are not possible.

\section{Training of upper airway muscles and hypoglossal nerve stimulation}

In OSA the obstruction of upper airways is associated with a reduced neuromuscular activity of the dilating muscles. Genioglossus is one of the important muscles in maintaining upper airway patency. It pushes the tongue forward and enlarges the cross sectional area of upper airways. Therefore stimulation or strengthening of the upper airway muscles should be helpful in OSA. Tongue muscle training by electrical stimulation is based on the fact that electrical stimulation of skeletal muscle has proven to be effective in the rehabilitation of skeletal muscles after injury. Intraneural stimulation of hypopglossal nerve and transcutanenous electrical stimulation of genioglossus muscle has shown an improvement of $\mathrm{AHI}$, day time somnolence and snoring. However there is not enough evidence to recommend it as a form of treatment at present.

\section{Oro pharyngeal exercises}

Oro-phayngeal exercises to strengthen the oro pharyngeal muscles and thereby improving OSA are another strategy that had been looked into. An RCT done by Puhan et $\mathrm{a}^{23}$ looked at the outcome after didgeridoo (a musical instrument) playing for four months. There was a reduction of $\mathrm{AHI}$. These methods have a limited role in the management of OSA. 


\section{Pharmacotherapy}

The benefits of pharmacotherapy are due to its effect on the change in respiratory drive, airway tone or surface forces that cause airway closure during sleep. Various studies have been done looking at the effects of tricyclic antidepressants, selective serotonin reuptake inhibitors, mirtazapine, cholinergic agonists, naltrexone, theophyllines, acetazolamide etc. At present there is no place for drug therapy in OSA.

\section{Nasal dilators}

Nasal vestibule is a major site of resistance to airflow in normal people. A high nasal resistance may increase snoring. It is hypothesized that nasal dilators might improve sleep and breathing by widening the nostrils. However, none of the published data supports the use of nasal dilators in OSA.

In the treatment of OSA it is useful to have multiple treatment options to suit the individual patient preference. Some of these methods may be attempted for those who are unable to tolerate or afford CPAP as a form of non-invasive therapy.

\section{References}

1. Terry Young, Paul E, Peppard, Daniel J. Gottlieb "Epidemiology of Obstructive Sleep Apnea". American Journal of Respiratory and Critical Care Medicine 2002; 165: $1217-39$

2. Sullivan CE, Issa FG, Berthon-Jones M, et al. Reversal of obstructive sleep apnoea by continuous positive airway pressure applied through the nares. Lancet 1981; 1: 862-5.

3. Yee BJ, Phillips CL, Banerjee D, et al. The effect of sibutramine-assisted weight loss in men with obstructive sleep apnoea. Int J Obes (Lond) 2007; 31: 161-8.

4. Charuzi I, Lavie P, Peiser J, et al. Bariatric surgery in morbidly obese sleep-apnea patients: short- and long-term followup. Am J Clin Nutr 1992; 55: Suppl. 2, 594S-596S.

5. Schwartz AR, Gold AR, Schubert N, et al. Effect of weight loss on upper airway collapsibility in obstructive sleep apnea. Am Rev Respir Dis 1991; 144: 494-8.

6. Chan AS, Lee RW, Cistulli PA. Non-positive airway pressure modalities: mandibular advancement devices/positional therapy. Proc Am Thorac Soc 2008; 5: 179-84.

7. Oksenberg A, Silverberg DS, Arons E, et al. Positional vs nonpositional obstructive sleep apnea patients: anthropomorphic, nocturnal polysomnographic, and multiple sleep latency test data. Chest 1997; 112: 629-39.

8. Loord H, Hultcrantz E. Positioner - a method for preventing sleep apnea. Acta Otolaryngol 2007; 127: 861-8.

9. Oksenberg A, Silverberg D, Offenbach D, et al. Positional therapy for obstructive sleep apnea patients: a 6-month follow-up study. Laryngoscope 2006; 116: 1995-2000.

10. Hans MG, Nelson S, Luks VG, et al. Comparison of two dental devices for treatment of obstructive sleep apnea syndrome (OSAS). Am J Orthod Dentofacial Orthop 1997; 111: $562-70$.

11. Mehta A, Qian J, Petocz P, et al. A randomized, controlled study of a mandibular advancement splint for obstructive sleep apnea. Am J Respir Crit Care Med 2001; 163: 1457-61.

12. Gotsopoulos H, Chen C, Qian J, et al. Oral appliance therapy improves symptoms in obstructive sleep apnea: a randomized, controlled trial. Am J Respir Crit Care Med 2002; 166: 743-8.

13. Johnston CD, Gleadhill IC, Cinnamond MJ, et al. Mandibular advancement appliances and obstructive sleep apnoea: a randomized clinical trial. Eur J Orthod 2002; 24: 251-62.

14. Barnes M, McEvoy RD, Banks S, et al. Efficacy of positive airway pressure and oral appliance in mild to moderate obstructive sleep apnea. Am J Respir Crit Care Med 2004; 170: 656-64.

15. Ferguson $\mathrm{KA}$, Ono T, Lowe AA, et al. A short-term controlled trial of an adjustable oral appliance for the treatment of mild to moderate obstructive sleep apnoea. Thorax 1997; 52 : 362-8.

16. Randerath WJ, Heise M, Hinz R, et al. An individually adjustable oral appliance vs continuous positive airway pressure in mild-to-moderate obstructive sleep apnea syndrome. Chest 2002; 122: 569-75.

17. Tan YK, L'Estrange PR, Luo YM, et al. Mandibular advancement splints and continuous positive airway pressure in patients with obstructive sleep apnoea: a randomized cross-over trial. Eur J Orthod 2002; 24: 239-49.

18. Hoekema A, Stegenga B, Wijkstra PJ, et al. Obstructive sleep apnea therapy. J Dent Res 2008; 87: 882-7.

19. Gagnadoux F, Fleury B, Vielle B, et al. Titrated mandibular advancement versus positive airway pressure for sleep apnoea. Eur Respir J 2009; 34: 914-20.

20. Walker-Engstrom ML, Tegelberg A, Wilhelmsson B, et al. 4-year follow-up of treatment with dental appliance or uvulopalato- pharyngoplasty in patients with obstructive sleep apnea: a randomized study. Chest 2002; 121: 739-46.

21. Marklund M, Stenlund H, Franklin KA. Mandibular advancement devices in 630 men and women with obstructive sleep apnea and snoring: tolerability and predictors of treatment success. Chest 2004; 125: 1270-8.

22. Deane SA, Cistulli PA, Ng AT, et al. Comparison of mandibular advancement splint and tongue stabilizing device in obstructive sleep apnea: a randomized controlled trial. Sleep 2009; 32: 648-53.

23. Puhan MA, Suarez A, Lo Cascio C, et al. Didgeridoo playing as alternative treatment for obstructive sleep apnoea syndrome: randomised controlled trial. BMJ 2006; 332: 266-70. 